\title{
Extract of Ginkgo biloba added to haloperidol was effective for positive symptoms in refractory schizophrenia
}

\author{
Zhang XY, Zhou DF, Zhang PY, et al. A double-blind, placebo-controlled trial of extract of Ginkgo biloba added to \\ haloperidol in treatment-resistant patients with schizophrenia.J Clin Psychiatry 2001 Nov;62:878-83. \\ QUESTION: In patients with chronic, refractory schizophrenia, is extract of Ginkgo \\ biloba (EGb) added to haloperidol more effective than placebo added to haloperidol?
}

Source of funding: Beijing Scientific and Technological New Stars Fund.

For correspondence: Dr X Y Zhang, Yale University School of Medicine, New Haven, CT, USA.

zhangxy99@

hotmail.com

\section{Design}

Randomised (unclear allocation concealment*), blinded (patients, healthcare providers, and outcome assessors)*, controlled trial with 12 weeks of follow up.

\section{Setting}

A psychiatric hospital in Beijing, China.

Extract of Ginkgo biloba (EGb) plus haloperidol v placebo plus haloperidol for refractory schizophreniat

\begin{tabular}{llllll} 
Outcome at 12 weeks & $\begin{array}{l}\text { EGb }+ \\
\text { haloperidol }\end{array}$ & $\begin{array}{l}\text { Placebo }+ \\
\text { haloperidol }\end{array}$ & RBI (95\% Cl) & NNT (Cl) \\
Clinical response & $57 \%$ & $38 \%$ & $51 \%(0.56$ to 37$)$ & $6(3$ to 179$)$ \\
\hline
\end{tabular}

†Clinical response $\geqslant 30 \%$ decrease in score on the Scale for the Assessment of Positive Symptoms. Other abbreviations defined in glossary; $\mathrm{RBI}, \mathrm{NNT}$, and $\mathrm{Cl}$ calculated from data in article.

\section{COMMENTARY}

EGb has been used for centuries in Asia. In the Western medical literature, controlled trials suggest efficacy of EGb in vascular and degenerative dementias, and in treatment resistant depression. Uncontrolled studies claim benefits of EGb in traumatic brain injury and antidepressant induced sexual dysfunction. ${ }^{12}$

One study of EGb in schizophrenia precedes the study by Zhang et al. Luo et al did a placebo controlled trial of EGb given adjunctively to neuroleptics in 545 patients with schizophrenia. ${ }^{3}$ EGb was associated with substantial improvements in global psychiatric ratings and in negative symptoms.

The trial by Zhang et al focused on recalcitrant patients who received standardised doses of haloperidol. EGb was associated with improvement in positive symptoms, and a greater number of "responders" for positive symptoms. One may have predicted and hoped that negative symptoms and cognitive deficits (which were not measured) would have improved. The positive symptoms of schizophrenia are the most likely to respond to current treatments; we don't know whether the improvements seen in this trial were because of an effect of EGb on the metabolism of haloperidol.

Given the paucity of treatments for refractory schizophrenia and the attractive safety profile of EGb, it may be worth considering EGb in certain cases. Indeed, many patients have elected to treat themselves with this widely available compound. Before recommending EGb for more general use, we need larger controlled trials that include treatment responsive patients. We also need to add to the presently small literature base concerning the interaction of EGb with other medications. ${ }^{4}$

Michael B Knable, DO Stanley Medical Research Institute Bethesda, Maryland, USA

1 Wong AH, Smith M, Boon HS. Herbal remedies in psychiatric practice. Arch Gen Psychiatry 1998;55:1033-44.

2 Oken BS, Storzbach DM, Kaye JA. The efficacy of Gingko biloba on cognitive function in Alzheimer disease. Arch Neurol 1998;55:1409-15.

3 Luo HC, Shen YC, Meng FQ. [Therapeutic effect of shuxuening combining neuroleptics for the treatment of chronic schizophrenia - a double blind study.] Zhongguo Zhong Xi Yi Jie He Za Zhi 1997;17:139-42.

4 Izzo AA, Ernst E. Interactions between herbal medicines and prescribed drugs: a systematic review. Drugs 2001;61:2163-75.

\section{Patients}

112 Han Chinese patients who were 18-60 years of age, had schizophrenia according to DSM-III- $R$ criteria for $\geqslant 5$ years, were resistant to treatment, and had a Clinical Global Impressions scale score of $\geqslant 4$. Exclusion criteria were medical illness, alcohol or drug abuse, receipt of vitamin C or $\mathrm{E}$ within 1 week of the start of the study, pregnancy, breastfeeding, or depressive symptoms. 109 patients (mean age 44 y, 58\% men) completed a 1 week placebo run in period; 103 (94\%) completed the study; all patients were included in the analysis of clinical response.

\section{Intervention}

Patients were allocated to EGb, $360 \mathrm{mg} /$ day, plus haloperidol, $0.25 \mathrm{mg} / \mathrm{kg}$ of body weight per day $(\mathrm{n}=56)$ or placebo plus haloperidol $(\mathrm{n}=53)$.

\section{Main outcome measures}

Change from baseline on the Brief Psychiatric Rating Scale (BPRS), the Scale for the Assessment of Negative Symptoms (SANS), and the Scale for the Assessment of Positive Symptoms (SAPS). Side effects were assessed using the Treatment Emergent Symptom Scale (TESS). Clinical response was defined as a $\geqslant 30 \%$ decrease in the BPRS, SAPS, or SANS total scores.

\section{Main results}

Analysis was by intention to treat. At 12 weeks, EGb group patients had lower SAPS scores than placebo group patients. The groups did not differ for change in scores on the BPRS or the SANS. Repeated measures multivariate analysis of variance showed a drug effect $(p=0.024)$ that remained when sex, age, and duration of illness were added to the analysis. Greater clinical response on the SAPS was seen in patients who received EGb than patients who received placebo (table). The groups did not differ for clinical response on the BPRS or the SANS. The groups did not differ for total scores on the TESS, and EGb group patients had greater decreases in behavioural toxicity and nerve system symptom subscores than placebo group patients.

\section{Conclusion}

In patients with chronic, refractory schizophrenia, extract of Ginkgo biloba added to haloperidol was more effective than placebo added to haloperidol in treating positive symptoms.

*See glossary. 